\title{
Lactobacillus GG reduced diarrhoea incidence in antibiotic treated children
}

Vanderhoof JA, Whitney DB, Antonson DL, et al. Lactobacillus GG in the prevention of antibiotic-associated diarrhea in children. J Pediatr 1999 Nov;135:564-8.

QUESTION: In children being treated with antibiotics, does co-administration of Lactobacillus GG (LGG) reduce the incidence of diarrhoea?

\section{Design}

Randomised (allocation concealed), blinded (clinicians, patients, and outcome assessors), placebo controlled trial with 10 days of follow up.

\section{Setting}

Primary care paediatric practice in Rapid City, South Dakota, USA.

\section{Patients}

202 children between 6 months and 10 years of age who had an acute infection of the upper or lower respiratory tract, urinary tract, soft tissues, or skin, and were prescribed a 10 day course of antibiotics. Exclusion criteria were chronic disease, serious acute infection, or diarrhoea at the start of antibiotic administration. 188 children (93\%) (median age 4 y, 55\% girls) completed the study.

\section{Intervention}

Children were allocated to LGG (CAG Functional Foods, Omaha, NE, USA) $(\mathrm{n}=93)$ or placebo $(\mathrm{n}=95)$. Children who weighed $<12 \mathrm{~kg}$ took 1 capsule (10 billion colony forming units of live LGG) daily with meals and those who weighed $\geqslant 12 \mathrm{~kg}$ took 2 capsules (20 billion colony forming units).

\section{Main outcome measures}

Incidence of diarrhoea ( $\geqslant 2$ liquid stools/d on $\geqslant 2$ occasions), stool frequency, and stool consistency (rated on an 8 point scale: $1=$ watery, $4=$ loose and soft, and $8=$ hard and dry).

\section{Main results}

Fewer children who received LGG had diarrhoea than did those who received placebo $\{\mathrm{p}<0.001\}^{*}$ (table). The mean duration of diarrhoea was slightly shorter in the LGG group than in the placebo group $(4.7 v 5.9 \mathrm{~d}$, $\mathrm{p}=0.05$ ). By day 10 , stool frequency was lower in the LGG group than in the placebo group (mean number of stools/day $1.4 v 2.0, \mathrm{p}<0.02$ ). By day 7 , fewer children who received LGG had a stool consistency score of $<4$ than did patients who received placebo $(\mathrm{p}<0.001)$ (table).

Source of funding:

ConAgra, Inc.

For correspondence: DrJ A Vanderhoof,

University Medical

Associates, $985160 \mathrm{NE}$

Medical Center

University of Nebraska, Omaha, NE

68198-5160, USA. Fax +14025592412 .

A modified version of thi abstract appears in

Evidence-Based

Medicine.
Lactobacillus $G G$ (LGG) v placebo for diarrhoea in children receiving 10 days of antibioticst

\begin{tabular}{|c|c|c|c|c|}
\hline Outcomes & LGG & Placebo & $\begin{array}{l}\text { RRR } \\
(95 \% \mathrm{Cl})\end{array}$ & NNT (Cl) \\
\hline Diarrhoea & $8 \%$ & $26 \%$ & $\begin{array}{l}71 \% \\
(39 \text { to } 87)\end{array}$ & $6(4$ to 13$)$ \\
\hline $\begin{array}{l}\text { Stool consistency } \\
\text { score }<4 \ddagger\end{array}$ & $17 \%$ & $48 \%$ & $\begin{array}{l}64 \% \\
(43 \text { to } 78)\end{array}$ & 4 (3 to 6$)$ \\
\hline
\end{tabular}

\section{Conclusion}

In children being treated with antibiotics, the coadministration of Lactobacillus $G G$ reduced the incidence and duration of diarrhoea, stool frequency, and watery or soft stool consistency.

*p Value calculated from data in article.

\section{COMMENTARY}

Gastrointestinal upsets are a well known side effect of broad spectrum antibiotic therapy. Although generally regarded as normal, our experience suggests that diarrhoea arising from the disturbance of the gastrointestinal microflora is enough to cause some parents to discontinue the antibiotics prescribed for their children.

In recent times, the consumption of live microbial organisms, or probiotics as they are collectively known, has been advocated both for improving health and preventing disease. With the advent of organisms able to withstand the action of gastric secretions and bile, claims of the ability of probiotics to maintain the microbial balance of the intestine during antibiotic therapy have gained momentum.

The trial done by Vanderhoof et al examines the influence of probiotic organism ingestion on gastrointestinal side effects during antibiotic therapy and supports the use of probiotics. The findings indicate that 6 children would need to be given LGG to prevent 1 additional child from having antibiotic induced diarrhoea and 4 children would need to be given LGG to prevent 1 additional child from having loose and soft or watery stools by day 7 of treatment.

The strength of the study lies in the blinding of all parents, clinicians, and researchers to the intervention. In part, this compensates for the fact that the outcome measures studied were subjective assessments made by parents. In addition to validation of parental reports of their children's gastrointestinal symptoms, information about the child's usual bowel habits and results of stool cultures ${ }^{1}$ would have strengthened the design. It is also important to note that the study was funded by the company that produces the drug, a fact that should alert the reader to potential bias.

Despite these design weaknesses, the results confirm the findings of an earlier study, ${ }^{1}$ and indicate that LGG may reduce gastrointestinal upsets associated with antibiotic therapy. It is recommended that probiotic therapy is considered by nurses and clinicians seeking to minimise antibiotic induced diarrhoea. Further research is needed about the effect of reducing antibiotic induced diarrhoea on child absenteeism from school and day care, use of health services, and compliance with antibiotic treatment. Jeanette Robertson, RN, MSc Nurse Consultant, Clinical Services Unit Princess Margaret/King Edward Hospitals Perth, Western Australia, Australia

1 Arvola T, Laiho K, Torkkeli S, et al. Prophylactic Lactobacillus GG reduces antibiotic-associated diarrhea in children with respiratory infections: a randomized study. Pediatrics 1999;104:e64. 